\title{
Using the new G.C. Laser Cleaning System for cleaning and surface preparation for re-gilding of a large outdoor bronze monument of Alexander Hamilton
}

\author{
Andrzej Dajnowski ${ }^{1 \star}$, Bartosz A. Dajnowski ${ }^{1,2}$ \\ 1 CSOS Inc., 900 S. Des Plaines Ave, Forest Park, IL 60130, USA \\ 2 GC Laser Systems Inc., 900 S. Des Plaines Ave, Forest Park, IL 60130, USA \\ * Corresponding author: adajnowski@csosinc.com
}

\begin{abstract}
In this paper, the conservation of the Alexander Hamilton Monument by John Angel from the Chicago Park District and the Ferguson Monument Fund will be discussed. The monument was installed in 1952 and was re-gilded in 1983. By 2015, over $80 \%$ of the gilding had failed and fallen off. Successful gilding of outdoor monuments requires very thorough surface preparation in order to remove all chlorides and active corrosion products. Inter-granular corrosion is a particular problem that is often difficult to resolve. In order for gilding to last, a bronze has to be as corrosion-free as possible. Traditional surface preparation techniques such as media blasting and ultra high-pressure washing carry the risk of causing physical changes to surface topography of the metal, closing surface pores and embedding salts. They may also leave active chlorides behind. In comparison, laser cleaning is more environmentally friendly as there is no contaminated media waste disposal and the precision and control during cleaning is unparalleled. The results of laser cleaning and surface preparation for re-gilding using the new tunable $1064 \mathrm{~nm}$ pulsed G.C. Laser Cleaning Systems, specifically designed for art conservation treatments, will be presented.
\end{abstract}

Keywords: laser cleaning, gilding, corrosion, primer, oil size, bronze

\section{Introduction}

The monument to Alexander Hamilton was commissioned by Kate Sturges Buckingham in the 1930's in Chicago and sculpted by John Angel [1]. Although one monument to Hamilton already existed in Chicago, Sturges strongly believed that the first Secretary of the Treasury and the man who created the financial foundation of the new republic deserved more recognition for what he had done for the country. In her will she donated
$\$ 1$ million dollars to the trustees of the Art Institute of Chicago for the creation of the monument to Hamilton. She also established a timeline of 10 years after which the money would no longer be available. The monument was likely gilded by that time and kept in indoor storage from the 1930s to the 1950s. There is no available information on the condition of the sculpture, the storage environment, or the surface preparation for the first gilding. However, it is known that war and the economical situation in the USA at 


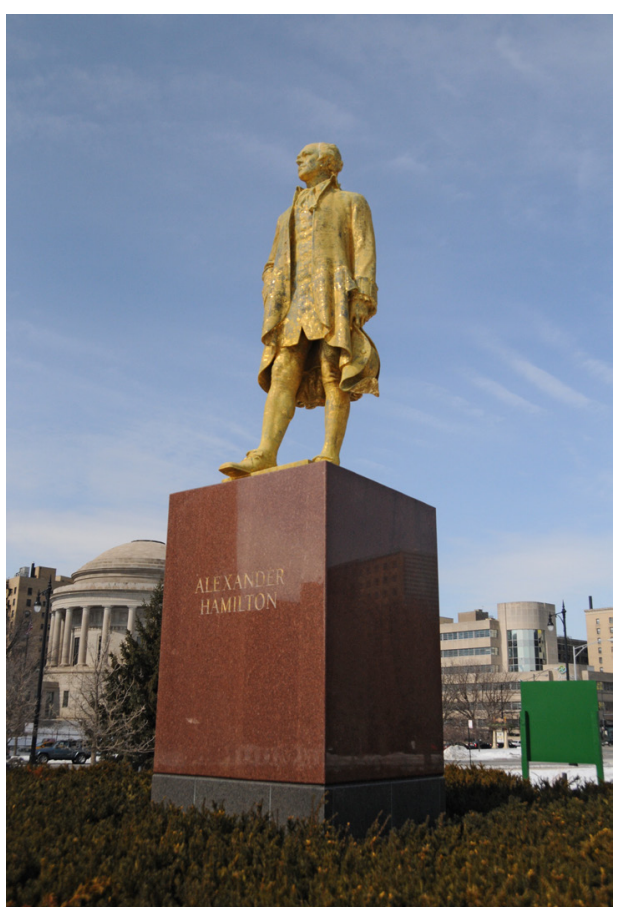

Fig. 1. Hamilton Monument before treatment (Lincoln Park, Chicago).

the time caused the delay of the installation. Although the sculpture was finished in clay in 1939 and cast in 1940, it was not installed until $1952[1,2]$. It is recognized that the sculpture was re-gilded in 1983 and within a decade the new re-gilding application had severely failed. The intent for this sculpture's appearance is for it to be gold, so its deteriorated condition was not acceptable.

The selection of an appropriate technique for treatment was discussed. In order to help ensure the longevity of the treatment, it was agreed that it was necessary to remove all of the copper alloy corrosion products from the bronze surface. The main goal of this treatment was to re-gild the sculpture and provide a stable surface finish that will last as long as possible outdoors. Laser cleaning was chosen as the safest and most controllable method for removing corrosion products from the bronze $[4,5,10]$. Other methods such as abrasive cleaning can leave behind or even embed chlorides inside metal pores and carry the risk of altering the surface. This is the first time a historic monumental bronze had been prepared for traditional oil re-gilding with laser ablation.

\section{Examination}

When examined from distance on a sunny day in 2015, the monument of Alexander Hamilton appeared to be golden in color. However, the yellow tone of the sculpture was not actual gold, but rather yellow due to the yellow zinc primer that covered the surface. The 3.91 meter tall, $1,587 \mathrm{~kg}$ bronze was heavily corroded and most of the gilding was missing. Furthermore, the corrosion was masked by the bright yellow tone of the primer and the reflection of the remaining traces of gold.

Upon closer examination, it was obvious that the surface of the sculpture was very deteriorated. Portable XRF, Raman, FTIR, and a $3 \mathrm{D}$ microscopy were used to analyze and examine the condition of the sculpture. The bronze was covered by green and black corrosion products, deteriorated yellow primer, and some traces of gold leaf. Once the sculpture was moved indoors to the CSOS conservation facility, the poor condition of the surface became more apparent (Fig. 2). The re-gilding done in 1983 had severely failed by the 1990s and sunlight reflecting off the yellow surface made the sculpture appear to be in better condition than it was. Poor preparation of the surface and failure to remove active corrosion products prior to re-gilding likely contributed to the fast deterioration of the new gilding. Corrosion 

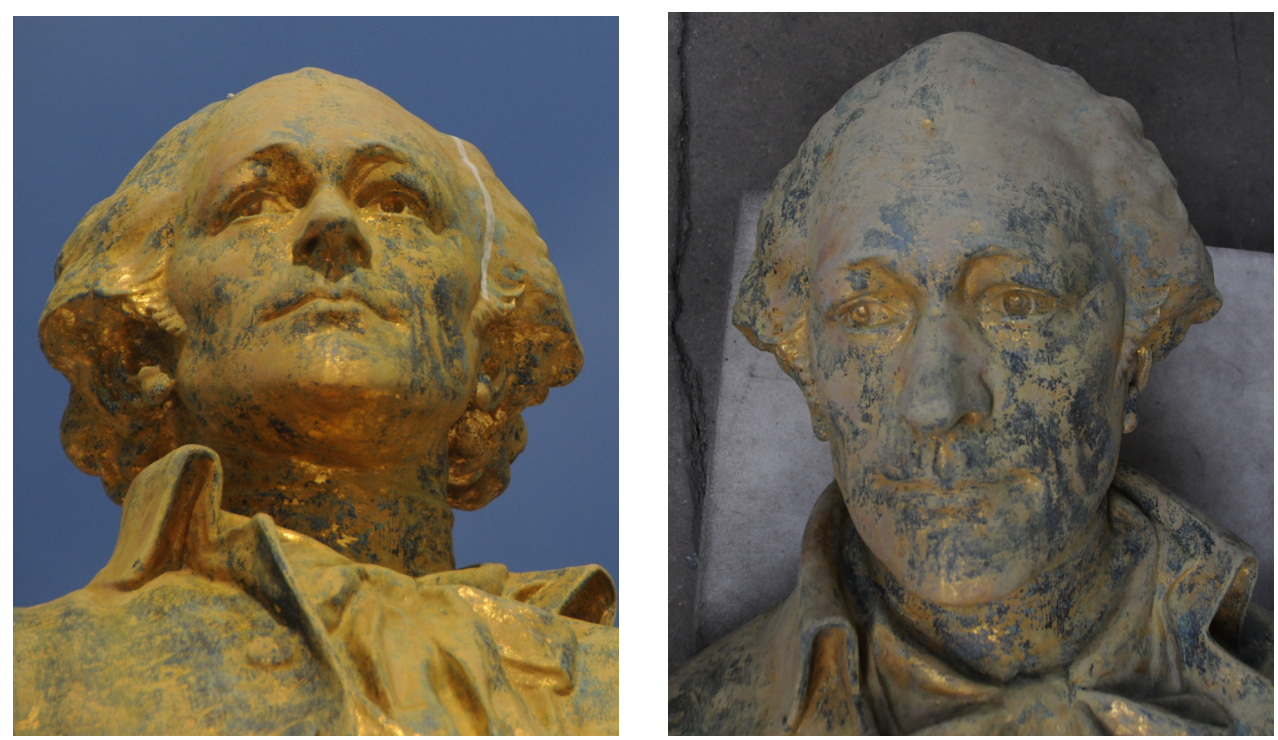

Fig. 2. Detail of the face. Left image taken on a sunny day while the sculpture was still in the park and the image on the right taken indoors without the presence of direct sunlight.

products found on the surface were examined using Raman and FTIR. They were identified as brochantite, copper acetate, antlerite, atacamite, paratacamite, copper oxalate; moreover, some gypsum was found.

\subsection{Raman scattering}

A Horiba XploRA PLUS Raman spectrometer was used with a $785 \mathrm{~nm}$ (red) diode laser operating at a laser power of $1 \%(300 \mathrm{~mW}$ total power). The instrument was frequency calibrated with a silicon reference standard. Data were collected over a range of 100 $\mathrm{cm}^{-1}$ to $2400 \mathrm{~cm}^{-1}$, and the spectral resolution of the instrument is $3 \mathrm{~cm}^{-1}$. A $50 \times$ objective was used for all data collection (J. Mass).

\subsection{FTIR}

A size 11 steel blade scalpel was used to remove small (millimeter sized) samples for molecular analysis by FTIR (Fourier trans- form infrared spectroscopy). Samples were mounted on a diamond half-cell support for transmission mode. Data were acquired and analyzed with a Thermo Scientific Nicolet iN-10 FTIR microscope controlled by OMNIC Picta software. A total of 128 scans were collected over a spectral range of $4000-650 \mathrm{~cm}^{-1}$ with a spectral resolution of 4 $\mathrm{cm}^{-1}$. A set of databases, including the IRUG (Infrared and Raman Users Group) database and a number of commercial databases, were used for identification (J. Mass).

\section{3. $X R F$}

The XRF used for the analysis was tripod-mounted and it was software controlled by a motorized X-Y stage. The resolution of the Elio XRF that was used is $<140 \mathrm{eV}$ at $\mathrm{Mn}$ $K a$ with spatial resolution based on beam size $\approx 1 \mathrm{~mm}$. The instrument used for this study was equipped with an $\mathrm{Rh} \mathrm{X}$-ray tube, and the data collected was normalized against 
standards to remove Rh peaks. XRF analysis of the metal established that the sculpture is bronze, that it is composed of $89.21 \%$ copper, $5.99 \%$ of tin, $2.24 \%$ zinc, $2.13 \%$ of lead, with trace amounts of $\mathrm{Ni}, \mathrm{Fe}, \mathrm{Ti}$ and $\mathrm{Cr}$ in it (error of 0.08 to $1.04 \%$ ). The alloy composition measurements were performed on an area of bare metal free of corrosion, primer and gold.

Figure 3 shows the surface of the deteriorated gilding and active corrosion products. The area photographed is approximately 1.0 $\mathrm{mm}$ wide. The gold and primer are cracked and separated from the actively corroding metal substrate.

The examination of samples of the gilding revealed that there are two double layers of dence that the gilding performed in 1983 was done without complete corrosion removal and without complete removal of the old primer. According to the historical information, the sculpture was "cleaned for one week by two workers" [2]. First of all, the surface was likely washed and mechanically cleaned. Secondly, the new zinc chromate primer was applied in two layers on top of the old gilding and then the surface of the bronze was re-gilded. This kind of surface preparation is not sufficient for the treatment of an outdoor sculpture that is to be gilded and exposed to Chicago weather. If the sculpture was kept in a controlled indoor environment, then perhaps the re-gilding would have survived in better condition. In the case of outdoor

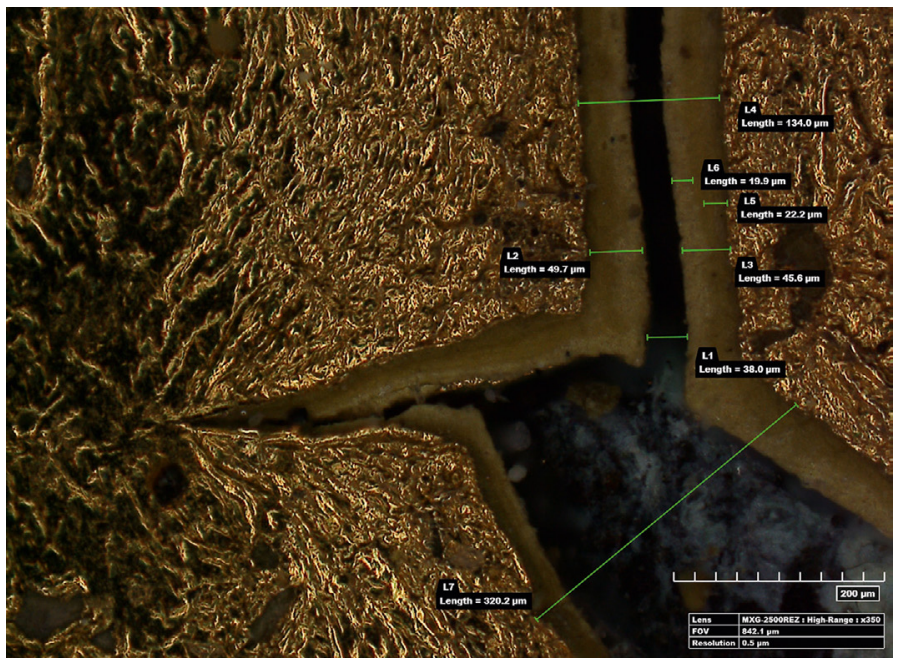

Fig. 3. 3D Micrograph illustrating the deterioration of the gilding and active corrosion. primer separated by a layer of gold in the middle. The top of the cross-section (Fig. 4) shows small areas of gold that was preserved on the top of the original primer. The dark bottom layer (under the primer) was composed typically of the green corrosion that was found in all of our samples. This sample illustrates that corrosion was undercutting the gold and primer layers. It provides evi- gilded bronzes, leaving deteriorated layers of primer and any surface corrosion under a new gilding campaign is a recipe for failure in a short period of time. The preservation of original and stable surface layers is usually preferred in conservation; however, it must also be taken into consideration that repeated re-treatments are not desirable for an object, and omitting or simply hiding inherent prob- 


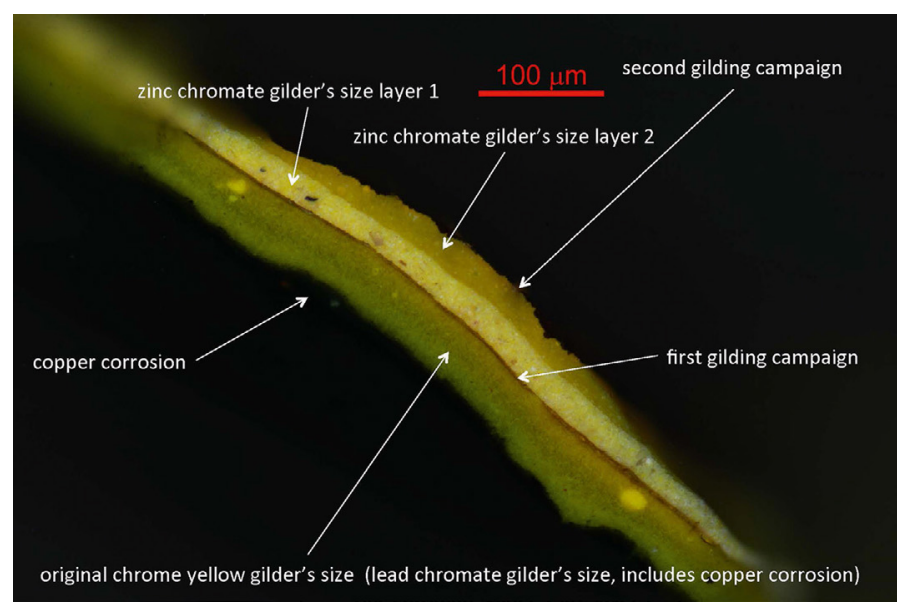

Fig. 4. Cross-section microscopy image of a sample of the gilding where layers from different gilding campaigns are visible (prepared by J. Mass and A. Finnefrock). lems on a surface is ultimately irresponsible. The removal of all corrosion products [3] and the deteriorated primer to a completely clean bronze surface was the only way to ensure a stable foundation onto which new gilding could be applied to last for decades. It must be noted that all aspects of this project were discussed with the owner. The importance of using laser ablation for this project was significant, because it allowed conservators to safely remove all surface deposits without disturbing surface topography of the bronze [4]. In particular, the G.C. Laser systems used for this project allowed for precise control over parameters and efficient cleaning of this large bronze.

\section{Treatment}

Historically, the surfaces of bronze sculptures that were about to be re-gilded were cleaned of corrosion using chemical cleaning, high pressure washing, sand blasting, or glass bead pinning to a bare bronze surface [6, 7]. Mechanical cleaning methods change the surface topography of the cleaned metal and repeated campaigns can result in the loss of surface details over time $[8,9]$. Chemical cleaning processes are messy and difficult to control. Moreover, they present the risk of contamination of the surroundings [7]. Consequently, laser cleaning was chosen as an effective alternative to other methods due to the high level of precision and control it offers, and because a properly calibrated laser system can remove corrosion products without damaging the underlying surface of the metal. Laser cleaning was proposed to the Art Institute of Chicago and Chicago Park District as an alternative to media blasting and was approved. To the authors' knowledge, this is the first time in conservation history that laser cleaning was used to prepare a monumental bronze for re-gilding. G.C. Laser Systems were used on this project due to their ease of use, high level of tunability, and unique circular scan pattern that ensures even an efficient distribution of energy across the surface. These systems are capable of producing a high frequency of laser pulses ranging from $10 \mathrm{kHz}-1,000 \mathrm{kHz}$. During this treatment we used the following $1064 \mathrm{~nm}$ laser systems: GC-1, GC-50, GC-100. 100ns to $250 \mathrm{~ns}$ pulses were used, depending on the area being cleaned. The GC- 1 allows for 

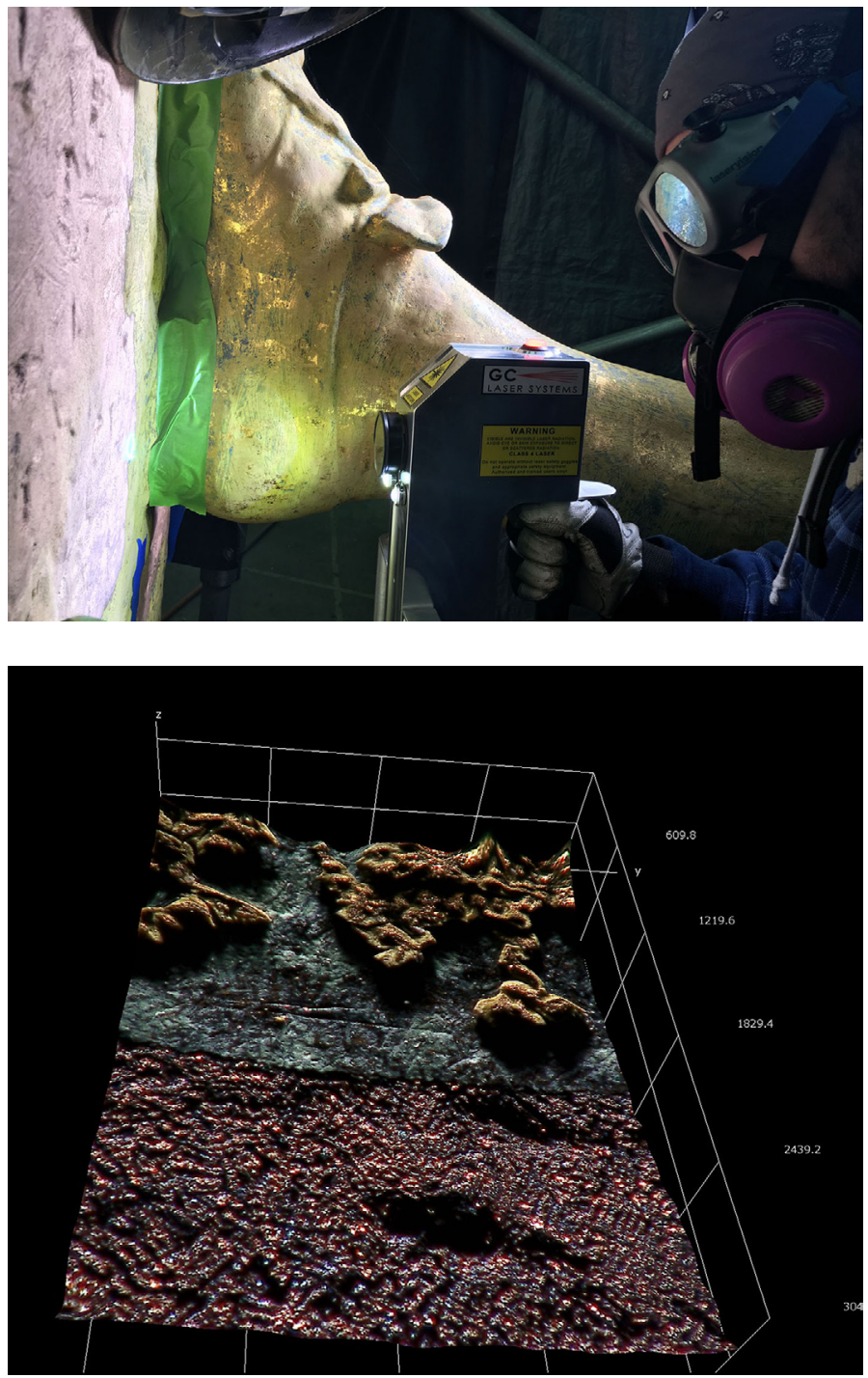

Fig. 5. Laser cleaning of the bronze surface performed by CSOS laser technician Christopher Ciaston. The laser has built-in lights to illuminate the workspace. An extraction trunk at the top left of the image is collecting fumes.

Fig. 6. Laser cleaning is able to remove old gilding, primer, and active corrosion products from the surface and uncover the dendritic structure of the bronze surface. Dimensions of examined area are: depth $3.05 \mathrm{~mm}$ and width $2.29 \mathrm{~mm}$. pulse duration to be selected by the operator. These lasers allowed for very precise and consistent surface cleaning.

Examination with a Hirox 3D microscope shows that the laser effectively removes failed gilding, old primer, and corrosion products to uncover the original dendritic crystal features of the bronze surface. Some of this dendritic pattern is visible in the green corrosion, but after laser cleaning it is very clearly uncovered. The laser is able to clean the surface without damaging the dendritic features of the original metal. A layer of cuprite can also be preserved.

During testing it was established that a 100 ns pulse with a pulse energy of 0.1 $\mathrm{mJ}$ and fluence of around $0.5-1.5 \mathrm{~J} / \mathrm{cm}^{2}$ removed the surface corrosion down to 


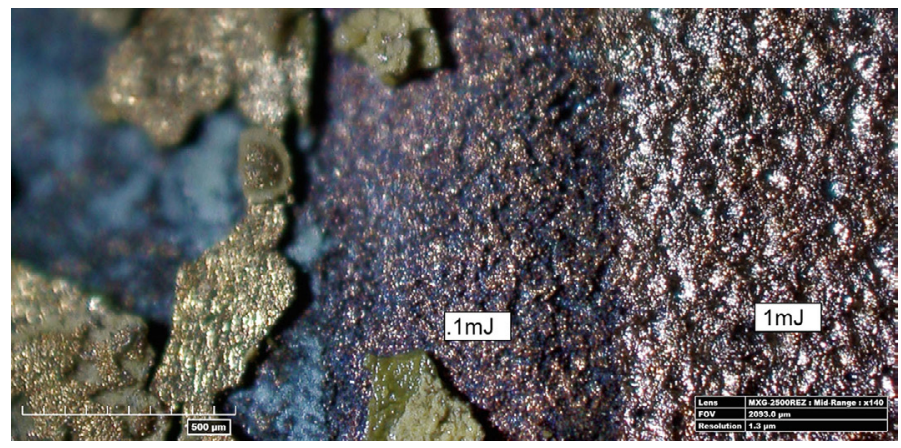

Fig. 7. Image illustrating the surface before laser cleaning on the left, the surface cleaned with $0.1 \mathrm{~mJ}$ pulses in the middle and $1 \mathrm{~mJ}$ pulses on the right.

a cuprite layer, but did not always remove all of the primer and gold material. In order to ensure all active corrosion, products were removed, 100ns-250ns pulses with a higher pulse energy of $1 \mathrm{~mJ}$ per pulse were used at a fluence range of $3-5.5 \mathrm{~J} / \mathrm{cm}^{2}$. Various optics were used to reach different focal depths with an in focus spot size of 200 microns with a pulse frequency ranging from $50 \mathrm{kHz}-300$ $\mathrm{kHz}$, depending on the area being cleaned and the size of the scan. Because this sculp- ture was going to be painted with a primer, it was desirable to clean down to a pure raw bronze surface to ensure that all corrosion products were removed. Examination with an Elio Portable XRF showed that chlorides were effectively removed from the laser cleaned area (Fig. 8).

The XRF was used to generate a false color map for chlorine and the laser cleaned square section is cool blue, indicating that chlorine is not present.

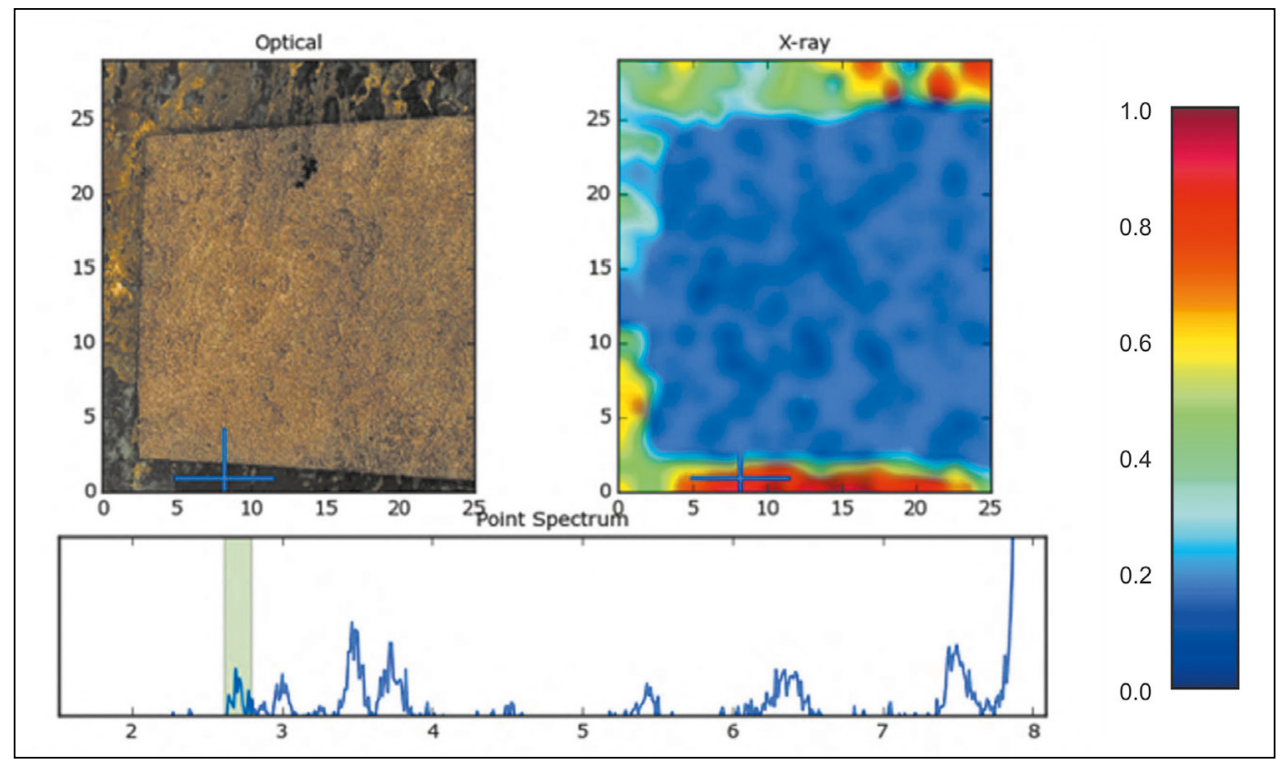

Fig. 8. Elio XRF chlorine distribution shown as a false color map. The laser cleaned area is cool blue, indicating low concentration of chlorine (image by N. Barbi). 


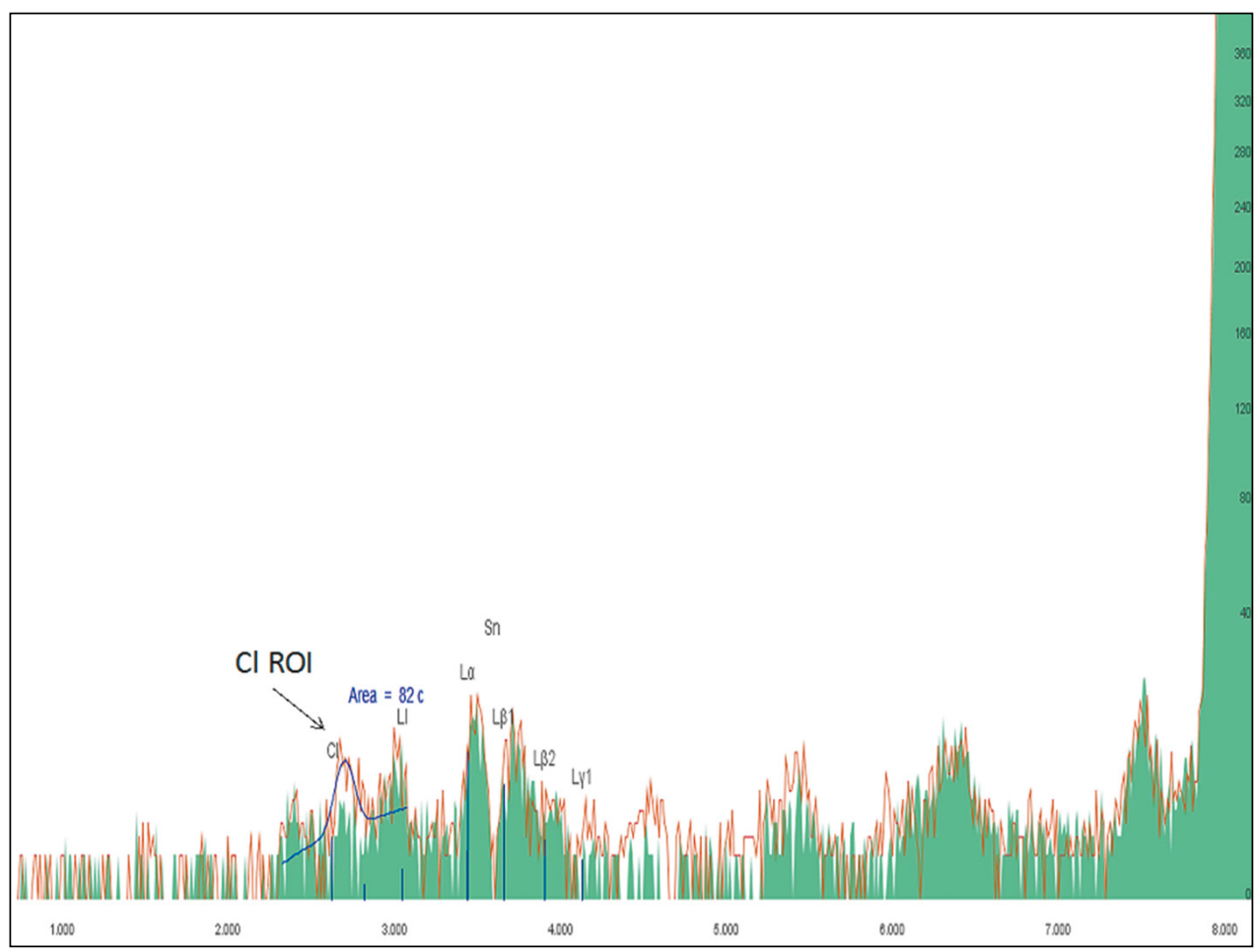

Fig. 9. Identification of chlorine by Elio XRF. The red spectrum is from the red region in the map and the green spectrum is from the blue region in the map in Fig. 8 (N. Barbi).

Each region of interest (ROI) in the XRF spectrum (Fig. 9) was mapped according to the false color scale: the red represents areas of the maximum intensity and blue represents the minimum intensity of the $\mathrm{Cl}$ signal. The scales of axes of images are given in millimeters. In the spectrum in Fig. 9 the horizontal axis scale is expressed in $\mathrm{keV}$, and the vertical axis is intensity. The intensity at the $100 \%$ value corresponds to 30 counts. Each spectrum was collected for 1 second (operator selected).

The signal of $\mathrm{Cl}$ is very week, because the concentration of $\mathrm{Cl}$ is low and spectrum integration time is short (1 second). Nevertheless, the spectral comparisons can reveal pixel to pixel differences, and by using maps, the human vision system is very effective at picking out the overall patterns. This pattern recognition skill of the human brain is one reason maps are so powerful. Fig. 9 illustrates 1-second spectra, one from a red area in the map (high intensity) and one from a blue area (low intensity). The difference in the $\mathrm{Cl}$ $\mathrm{ROI}$ can be readily seen. The fitting calculates a peak integral of 82 counts, the square root of which is about 9 , with a sigma of $11 \%$ (N. Barbi). The data indicates that chlorides have been successfully removed by the laser cleaning process.

The upper portion of Fig. 10. presents 3D image of the area cleaned with laser. The lower diagram shows surface topography of the cleaned metal. It should be noted that there are no topographic changes in the cleaned zone. The above image illustrates that 


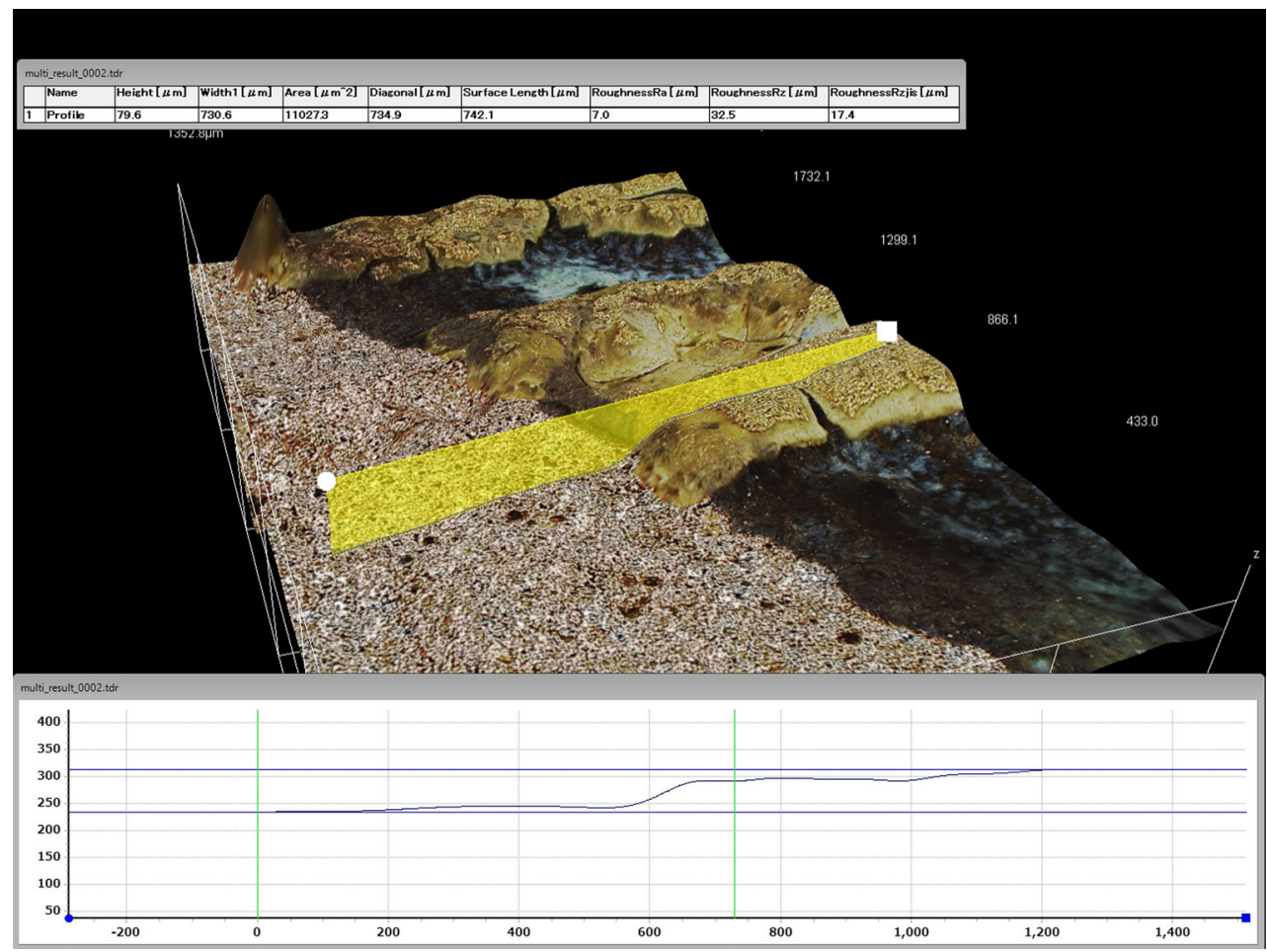

Fig. 10. Hirox 3D depth profile of the laser cleaned area shows that approximately 50 microns of corrosion and old gilding are removed by the laser.

it is possible to remove the corrosion products using laser ablation process and keep the original surface intact. In addition, the profile shows that after laser cleaning there was no change in the surface topography.

During treatment, in order to make sure that the bronze was free of any hidden copper chlorides, the surface of the sculpture was sprayed with pure distilled water after laser cleaning to encourage any remaining chlorides to emerge. Some porous areas with deep chloride penetration developed new green corrosion spots 24 hours after being exposed to water approximately 1 to $2 \mathrm{~mm}$ in diameter and were laser cleaned again. The surface was visually inspected each day. This process was repeated as necessary in areas where chlorides continued to emerge from the metal until these areas were completely clean and stable.

The sculpture after laser cleaning was degreased with the use of acetone and ethyl alcohol. Two coats of epoxy based zinc chromate primer manufactured by PPG were applied to the entire surface of the sculpture.

The primer was allowed to cure for five days and 12 hour Lefranc oil size was applied to the areas that were going to be gilded. Rosanobel double thickness 23.75 karat gold was used for gilding the monument. The head, shoulders, base and upper surfaces of the sculpture were gilded twice. The application of second layer of gold to those areas will provide longer lasting protection for the surface of the bronze. 


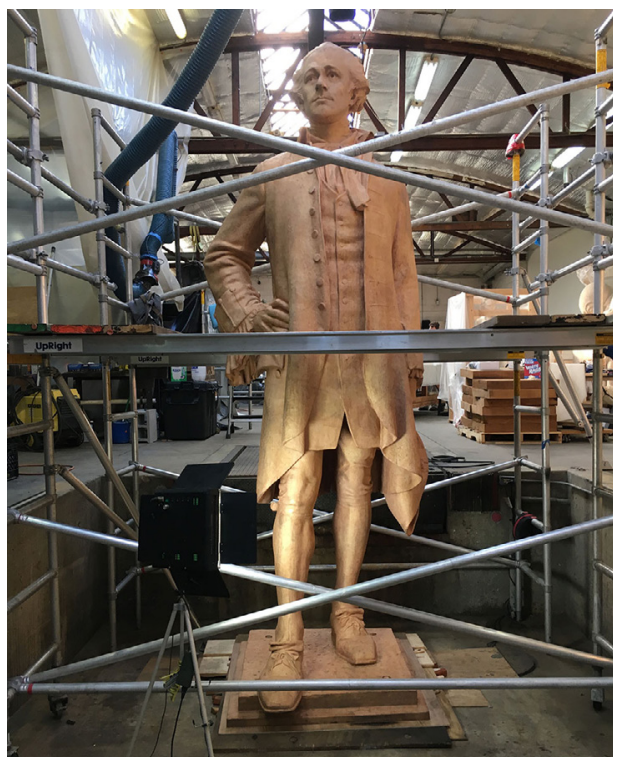

Fig. 11. Hamilton Monument entirely cleaned of the surface corrosion with the use of the laser ablation process.

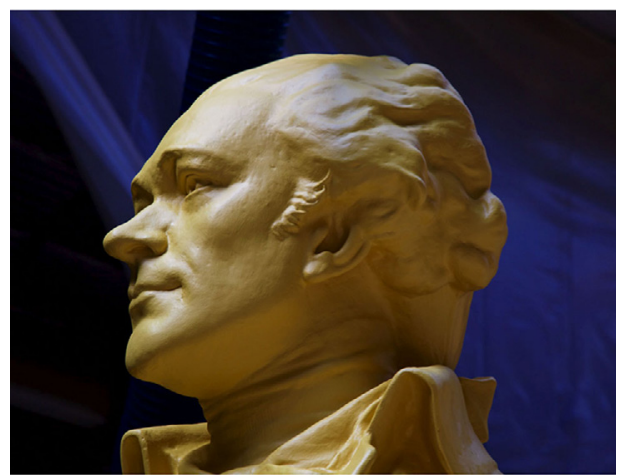

Fig. 12. Face of the sculpture after coating with zinc chromate.
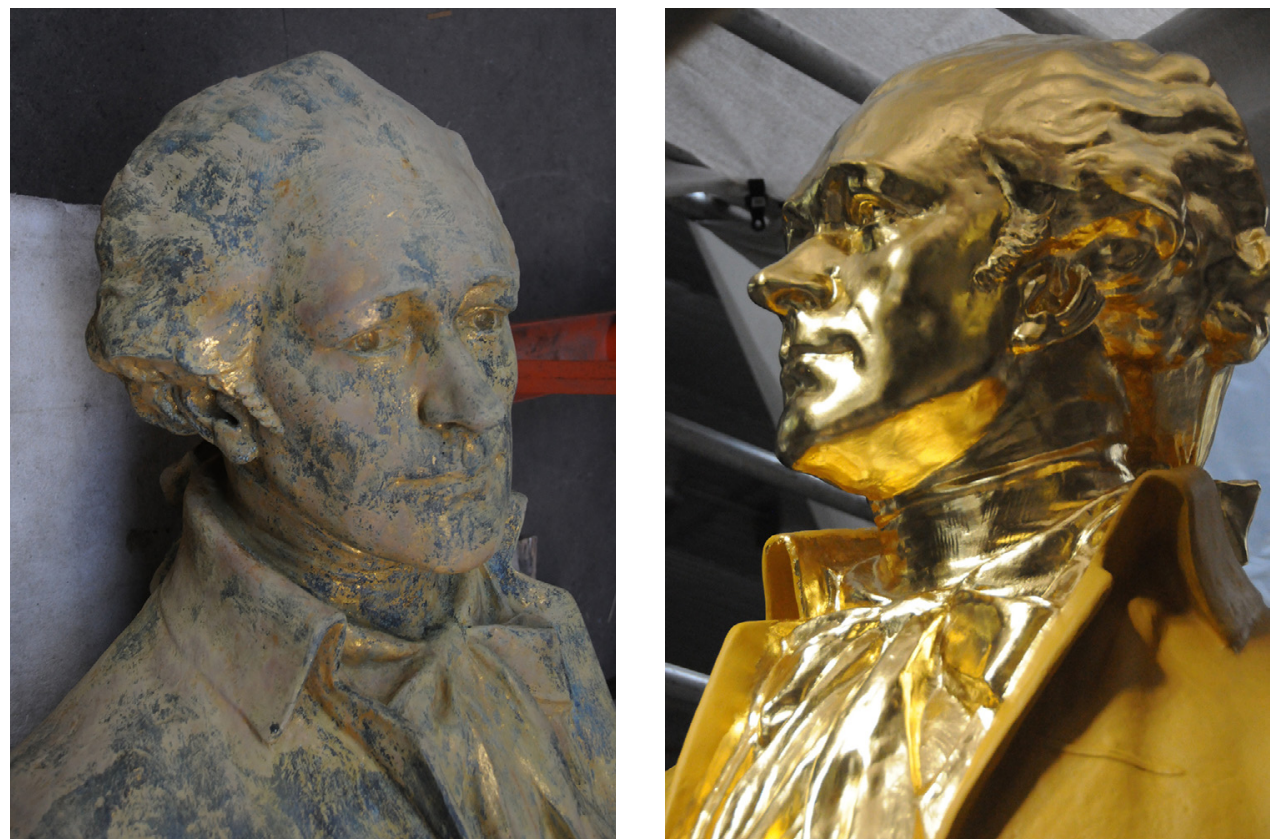

Fig. 13. On the left - the image of the sculpture before treatment, on the right - gilded face and chest of the figure. The jacket is primed before gilding. 


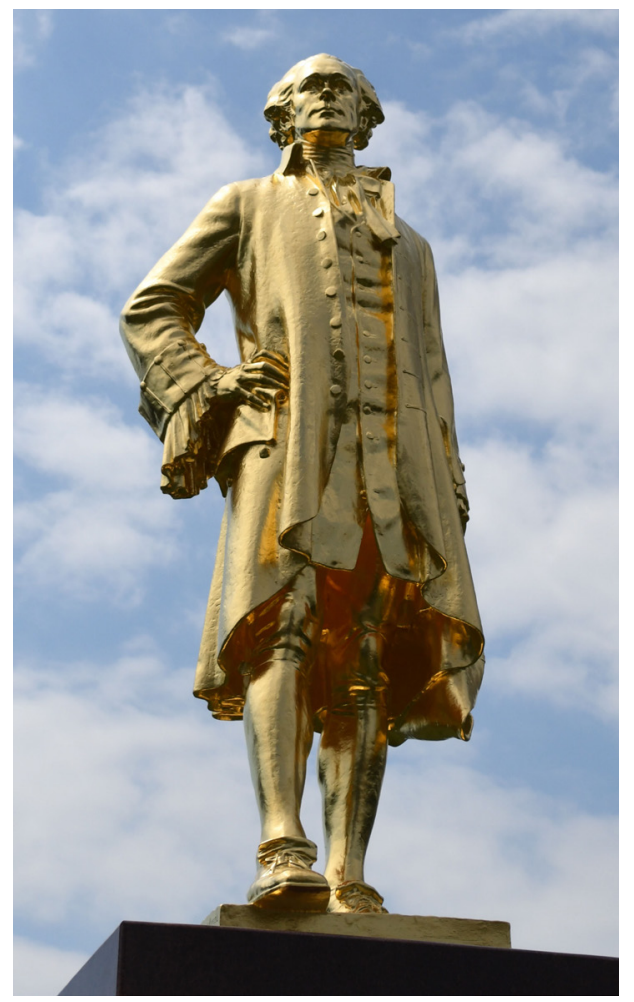

Fig. 14. Hamilton sculpture after gilding reinstalled in Lincoln Park.

\section{Conclusions}

The laser cleaning process provided us with a clean surface of metal that was corrosion-free and undamaged. After laser cleaning, any chlorides that were deeper in the metal were encouraged to activate and emerge by being sprayed with distilled water. Any chlorides that bloomed after being exposed to water were removed with the laser. This process was repeated as necessary until all active chlorides were successfully removed. The very high level of laser parameter control using G.C. Laser Systems allowed us to completely remove corrosion while preserving the topography of the surface. The bronze was corrosion-free, which will provide long-lasting treatment results. Obviously, the sculpture will require periodic maintenance such as washing with deionized water to remove contaminants, e.g. winter salts and bird droppings from the surface. According to our knowledge, this was the first use of laser ablation process for the preparation of a large monument for gilding. The high precision of corrosion removal with G.C. lasers provided a very clean surface of bronze for gilding. The overall treatment of the iconic Hamilton monument proved to be successful. The monument is being held for safe storage over the winter at CSOS and will be reinstalled in Lincoln Park in Chicago in the spring of 2017. At the moment, laser ablation cleaning appears to be the best alternative to traditional cleaning methods for preparing bronze sculptures for gilding.

\section{Acknowledgements}

We owe many thanks for help and support during this project to: Susanne Schnepp, Art Institute of Chicago, Michael Fus, Chicago Park District, Jennifer Mass, Ph.D. Scientific Analysis of Fine Art, LLC, Adam Finnerfrock, Ph.D., Scientific Analysis of Fine Art, LLC, Nicholas C. Barbi, Ph.D., nSynergies Inc., and CSOS staff: Christopher Ciaston, Artur Konarzewski, Cathereen Lee, Robert Zarycki, Tadeusz Mlynarczyk, Jonathan Murach.

\section{References}

[1] I. Bach, M. Lackritz Gray, A guide to Chicago's Public Sculpture, The University of Chicago Press, Chicago 1983, p. 150.

[2] J. Riedy, Chicago Sculpture, University of Illinois Press, Urbana 1981, pp. 14, 16, 224.

[3] L.B. Brostoff, Coating Strategies for the Protection of Outdoor Bronze Art and Ornamentation, University of Amsterdam, Amsterdam 2003, pp. 3-4.

[4] A. Dajnowski, "Laser as a Cleaning Tool for the Treatment of Large Scale Bronze Monuments", in: 
Lasers in the Conservation of Artworks - Lacona VII Proceedings, M. Castillejo et al. (Eds.), Taylor \& Francis Group, London 2008, pp. 303-308.

[5] S. Siano, R. Salimbeni, "Advances in Laser Cleaning of Artwork and Objects of Historical Interest: The Optimizes Pulse Duration Approach", Acc. Chem. Res., 43 (2010) 739-750, DOI: 10.1021/ar900190f.

[6] T. Drayman-Wiseser, Gilded Metals History, Technology and Conservation, Archetype Publishing Ltd, London 2000, p. 337, 349.

[7] D.A. Scott, Copper and Bronze in Art Corrosion, Colorants, Conservation, Getty Trust Publications, Santa Monica CA 2002, pp. 122-144.
[8] W.T. Chase, N. F. Veloz, "Some Considerations in Surface Treatment of Outdoor Metal Sculptures", in: Preprints of Papers Presented at the Thirteenth Annual Meeting: Washington, D.C., 22-26 May 1985, American Institute for Conservation of Historic and Artistic Works, A.I.C. 1985, pp. 23-25.

[9] T. Draysman-Weisser, "Dialogue/89, The Conservation of Bronze Sculpture in the Outdoor Environment: A Dialogue Among Conservators, Curators, Environmental Scientist, and Corrosion Engineers", NACE, Huston, Texas, USA, 1992.

[10] M. Giust, G.M. Radke, The Gates of Paradise: From the Renaissance Workshop of Lorenzo Ghiberti to the Restoration Studio, Giunti Industrie Grafiche S.p.A., Prato 2012. 